\title{
Conquering Hunger in a Newborn with Cleft Palate
}

\author{
Dr. Alok Dubey* \\ Associate professor, Pedodontics Department, College of Dentistry, Jazan University, Saudi Arabia
}

*Corresponding Author: Dr. Alok Dubey, Associate professor, Pedodontics Department, College of Dentistry, Jazan University, Saudi Arabia

\section{GUEST EDitorial}

Cleft lip and palate are one of the most common structural birth defects. Its consequences affect several systems and functions that include feeding, facial growth, dentition, speech as well as the social and psychological problems which have an impact on the child and parent [1]. Neonates born with cleft lip and palate have oro-nasal communication which diminishes the ability to create negative pressure necessary for suckling [2,3].Compressing the nipple between tongue and hard palate to squeeze out the liquid becomes difficult.

Feeding a child with cleft is no less than a battle of patience for parents. Parents might feel helpless as the child longs for milk. Feeding appliances (Obturator) are often required by such patients to conquer this problem by creating a seal between the oral and nasal cavities and helping the infant to express milk.

The initial and crucial step in the fabrication of the feeding appliances is the impression procedure. The impression is made when the infant is fully awake without anaesthesia or premedication [4]. The infant should be able to cry during. impression procedure as not crying may be indicative of airway blockage [5]. Later the feeding appliance is fabricated in a dental laboratory.

Regular follow up with dentist is required as the appliance needs to be changed every 2-3 months till cleft repair is planned. This is so as the child is growing and the appliance might not fit the upper jaw.
Thus we see that feeding time in cleft patient is prolonged and fatigues both the baby and the parents [6]. It is important that pediatrician asks for a consultation with a pediatric dentist so as to address the immediate problem of interference in feeding of a new born. Pediatric dentist shall make feeding appliance that will seal the communication between oral and nasal cavity and infant is able to express milk [7].

\section{REFERENCES}

[1] Reid J. A review of feeding interventions for infants with cleft palate. Cleft Palate Craniofac J. 2004; 41:268-78.

[2] Osuji OO. Preparation of feeding Obturator for infants with cleft lip and palate. J Clin Pediatric Dent. 1995; 19:211-4.

[3] Choi BH, Kleinbeririz J, Joos U, Komposch G. Sucking efficiency of early orthopedic plate and teats in infants with cleft lip and palate. Int J Oral Maxillofac Surg. 1991; 20:167-9.

[4] Ravichandra KS, Vijayaprasad KE, Vasa AA, et al. A new technique of impressionmaking for an obturator in cleft lip and palate patient. J Indian SocPedodPrevDent 2010; 28:311-14.

[5] Chandna P, Adlakha VK, Singh N. Feeding obturator appliance for an infant with cleft lip and palate. J Indian SocPedodPrev Dent 2011; 29:71-3.

[6] Dubey A, Mujoo S, Khandelwal V, Nayak PA. Simplified design and precautionary measures in fabrication of a feeding obturator for a newborn with cleft lip and palate. BMJ Case Rep 2013; 2013. pii: Bcr2013010465.

[7] Choi BH, Kleinheinz J, Joos U, et al. Sucking efficiency of early orthopaedic plateand teats in infants with cleft lip and palate. Int J Oral MaxillofacSurg 1991; 20:167-9.

Citation: Dr. Alok Dubey, Conquering Hunger in a Newborn with Cleft Palate. ARC Journal of Nursing and Healthcare. 2020; 6(1):16. DOI: doi.org/ 10.20431/2455-4324.0601003.

Copyright: (1) 2020 Authors. This is an open-access article distributed under the terms of the Creative Commons Attribution License, which permits unrestricted use, distribution, and reproduction in any medium, provided the original author and source are credited. 